\title{
Analisis Perbaikan Kualitas Produk Carton Box di PT XYZ Dengan Metode DMAIC dan FMEA
}

\author{
Arif Rahman ${ }^{1}$, Surya Perdana ${ }^{* 2}$
}

\begin{abstract}
Abstrak - PT XYZ merupakan perusahaan manufaktur yang bergerak dalam bidang pembuatan carton box berbagai jenis produk kemasan untuk industri. Perusahaan ini melakukan produksi sesuai dengan pesanan. Selama melakukan proses produksi perusahaan ini mengalami permasalaah berupa cacat produk, banyak produk yang dihasilkan tidak sesuai dengan spesifikasi dan harapan pelanggan. Tujuan penelitian ini adalah untuk mengidentifikasi tingkat kecacatan yang dominan, menganalisis faktor penyebab kecacatan, serta membuat usulan perbaikan guna peningkatan kualitas produk carton box. Analisis data dalam penelitian ini menggunakan metode DMAIC (Define, Measure, Analyze, Improve dan Control) dan Failure Modes Effect Analysis (FMEA). Berdasarkan hasil identifikasi diperoleh kecacatan yang paling dominan terjadi pada proses produksi carton box adalah cacat cetakan gambar yaitu sebanyak 50,1\% dari total kecacatan yaitu sebanyak 137.361 pcs. Hasil analisis FMEA menunjukkan komponen paling besar dengan nilai RPN sebesar 280 cacat produk disebabkan oleh faktor manusia. Usulan perbaikan yang disarankan kepada perusahaan yaitu dengan memperketat pengawasan selama proses produksi agar produk carton box sesuai dengan standar, serta dilakukan pelatihan kepada operator.
\end{abstract}

Kata Kunci-Kualitas, Cacat Produk, Six Sigma, DMAIC, FMEA.

Abstract - PT XYZ is a manufacturing company engaged in the manufacture of carton boxes for various types of industrial packaging products. This company produces according to order. During the production process, this company experienced problems in the form of product defects, many of the products produced were not in accordance with customer specifications and expectations. The purpose of this study was to identify the dominant level of defect, analyze the causes of disability, and make suggestions for improvements to improve the quality of carton box products. Data analysis in this study used the DMAIC method (Define, Measure, Analyze, Improve and Control) and Failure Mode Effect Analysis (FMEA). Based on the identification results, the most dominant defect that occurs in the carton box production process is image printing defects, which are $50.1 \%$ of the total defects, which are 137,361 pcs. The results of FMEA analysis show that the largest component with an RPN value of 280 product defects is caused by human factors. Recommendations for improvements suggested to the company are tightening supervision during the production process so that carton box products comply with standards, as well as training for operators.

Keywords-Quality, Product Defects, Six Sigma, DMAIC, FMEA.

\section{PENDAHULUAN}

$\mathrm{D}$ alam memproduksi suatu produk aspek terpenting yang harus diperhatikan oleh perusahaan adalah kualitas. Setiap perusahaan harus menjaga dan memperhatikan kualitas produk yang dihasilkan. Adanya persaingan pasar dimana banyak perusahaan yang menawarkan produk sejenis memicu perusahaan untuk terus meningkatkan kualitas produk yang dihasilkan agar dapat mempertahankan pelanggan. Dengan demikian, kualitas dapat dipergunakan untuk memenangkan persaingan [1].

PT XYZ merupakan perusahaan manufaktur yang bergerak dalam bidang pembuatan carton box berbagai jenis produk kemasan untuk industri. Perusahaan ini melakukan produksi sesuai dengan pesanan. Selama melakukan proses produksi perusahaan ini mengalami permasalaah berupa cacat produk, banyak produk yang dihasilkan tidak sesuai dengan spesifikasi dan harapan pelanggan. Tujuan penelitian ini adalah untuk mengidentifikasi tingkat kecacatan yang dominan,

A. Rahman, Universitas Indraprasta PGRI, Jakarta (email: arif.rahman0876@gmail.com).

S. Perdana, Universitas Indraprasta PGRI, Jakarta (email: suryaperdana.st.mm@gmail.com). menganalisis faktor penyebab kecacatan, serta membuat usulan perbaikan guna peningkatan kualitas produk carton box.

Perbaikan kualitas bukan hanya dilakukan pada produk akhir, melainkan juga pada proses produksinya atau masih dalam proses produksi (work in process), sehingga jika diketahui terdapat cacat atau kesalahan masih dapat diperbaiki [2]. Metode six sigma sering digunakan perusahaan untuk pengendalian kualitas produk dengan cara meminimasi jumlah defect. Aplikasi six sigma berfokus pada cacat dan variasi, dimulai dengan mengidentifikasi unsur-unsur kritis terhadap kualitas dari suatu proses hingga memberikan usulan-usulan perbaikan terkait cacat yang timbul [3]. Six sigma merupakan proses peningkatan terusmenerus, yang lebih mengutamakan pada tahapan DMAIC (define, measurement, analyze, improve, control) [4]. DMAIC merupakan sebuah metode perbaikan kualitas yang langsung memecahkan masalah yang berkaitan dengan mutu sebuah produk hingga pada penyebab utamanya [5].

Metode DMAIC merupakan pendekatan yang lengkap untuk melakukan pengendalian dan perbaikan kualitas karena dimulai dengan mengidentifikasi masalah sampai melakukan pengendalian serta memberikan usulan untuk melakukan perbaikan [6]. Perbaikan yang dilakukan 
salah satunya adalah dengan menggunakan metode Failure Mode Effect Analysis (FMEA). Metode FMEA ini adalah Metode analisis yang digunakan untuk mengetahui atau mengamati apakah suatu tindak kegagalan (failure) dapat dianalisis atau diukur sehingga dapat diantisipasi, dimitigasi ataupun dicegah baik tingkat kegagalannya ataupun efek negatif yang timbul sebagai faktor output-nya [7].

Failure Mode and Effects Analysis (FMEA) adalah suatu prosedur terstruktur untuk mengidentifikasi dan mencegah sebanyak mungkin mode kegagalan [8]. Failure Mode and Effects Analysis (FMEA) adalah salah satu metode yang sistematis dan sangat terstruktur untuk menganalisis kegagalan. FMEA mengidentifikasi dan memprioritaskan kemungkinan kegagalan atau cacat. Dalam penghitungan risiko FMEA menggunakan indikator (RPN), yang didefinisikan sebagai produk keparahan (S), insiden (O), dan deteksi (D) kegagalan [9]. FMEA dipergunakan setelah mendapatkan faktor yang mempengaruhi kegagalan atau kecacatan dengan tujuan didapatkan faktor mana yang memerlukan penanganan lebih lanjut [10]. RPN dihitung dengan cara melakukan pembobotan dengan 3 aspek yaitu Severity, Occurrence dan Detection, dalam skala 1-10 sehingga akan didapatkan nilai RPN (Risk Priority Number) masing-masing penyebab [11].

\section{METODE DAN PROSEDUR}

Penelitian ini merupaka penelitian kuantitatif, dimana pengumpulan data dilakukan dengan cara pengamatan secara langsung terhadap obyek yang diteliti agar didapat data yang relevan. Metode pengumpulan data dilakukan dengan cara observasi secara langsung, wawancara terhadap pimpinan/karyawan perusahaan, penyebaran kuesioner, dan kajian pustaka. Setelah data didapatkan, selanjutnya dilakukan pengolahan data dengan tahapan:

\section{A. Define (mengidentifikasi masalah)}

Dilakukan identifikasi secara jelas masalah yang dihadapi oleh perusahaan. Memetakan proses kegiatan guna memahami dan melokalisir masalah. Memilih alternatif tindakan untuk menanggulangi meluasnya problem. Merumuskan parameter keberhasilan proyek mengingat luasnya ruang lingkup, tingkat penyelesaian masalah sebagai sasaran yang dibidik, tersedianya perlengkapan, tenaga pelaksana, waktu dan biaya. Mendefinisikan Critical to Quality (CTQ) dari hasil proses produksi carton box, Diagram SIPOC, dan sebagainya. Diagram SIPOC merupakan diagram yang menggambarkan aktivitas atau sub proses pada suatu proses bisnis secara mayor. Diagram SIPOC digunakan sebagai alat bantu untuk menentukan batasan-batasan dan elemen-elemen penting dari sebuah proses.

\section{B. Measure (pengukuran)}

Dilakukan pehaman terhadap proses internal perusahaan yang sangat potensial dalam mempengaruhi cacat proses produksi carton box dengan cara menentukan karakteristik kualitas (CTQ). Kemudian mengukur besaran penyimpangan yang terjadi dibandingkan dengan standar mutu yang telah ditetapkan dengan cara menghitung Defect Per Million Opportunities (DPMO).
DPMO merupakan ukuran kegagalan dalam program peningkatan kualitas Six sigma, yang menunjukkan kegagalan per sejuta kesempatan. Target dari pengendalian kualitas Six sigma Motorola sebesar 3,4 DPMO diintepretasikan sebagai dalam suatu unit produk tunggal terdapat rata-rata kesempatan untuk gagal dari suatu karakteristik CTQ adalah hanya 3,4 kegagalan per satu juta kesempatan. Besarnya kegagalan per satu juta kesempatan (DPMO) dihitung berdasarkan persamaan yaitu:

$D P M O=\frac{\text { defect }}{\text { unit } x \text { oppurtunity }} \times 10^{6}$

Dalam pendekatan Six Sigma, proses yang terjadi dalam suatu pabrik atau perusahaan diukur kerjanya dengan menghitung tingkat sigmanya. Semakin nilai sigma mendekati enam sigma, maka kinerja dari proses dapat dikatakan sangat baik. Dasar perhitungan tingkat sigma adalah menggunakan DPMO untuk data variabel. Besarnya tingkat sigma dihitung menggunakan bantuan software Microsoft Excel berdasarkan formula yaitu:

Nilai sigma $(\sigma)=\operatorname{NORMSINV}\left(\frac{10^{6}-D P M O}{10^{6}}+1,5\right)$

Control chart merupakan alat yang dapat menvisualisasikan variasi-variasi yang terjadi pada kecenderungan dan penyebaran pusat dari suatu kumpulan observasi sehingga suatu proses dapat dimonitor dan dikendalikan. Peta kontrol dibuat untuk mengetahui apakah proses dalam kendali dan untuk memonitor variasi proses secara terus-menerus. Peta $\mathrm{p}$ menggambarkan bagian yang ditolak karena tidak sesuai dengan spesifikasi yang diinginkan. Perhitungan untuk 12 periode jenis kecacatan pada produk Bedasarkan data yang ada, didapat nilai mean $\mathrm{p}(\mathrm{CL})$ sebagai berikut:

$\overline{\mathrm{p}}=\frac{\sum n p}{\sum n}$

Batas kelas Atas (UCL) dapat dihitung seperti di bawah ini:

$U C L=\overline{\mathrm{p}}+3 \sqrt{\frac{\overline{\mathrm{p}}(1-\overline{\mathrm{p}})}{n}}$

Batas Kelas Bawah (LCL) dapat dihitung seperti di bawah ini:

$L C L=\overline{\mathrm{p}}-3 \sqrt{\frac{\overline{\mathrm{p}}(1-\overline{\mathrm{p}})}{n}}$

\section{Analyze (analisis)}

Dilakukan upaya memahami mengapa terjadi penyimpangan dan mencari alasan-alasan yang mengakibatkan terjadinya cacat carton box. Analisis dilakukan dari data yang telah dikumpulkan dengan menggunakan alat bantu kualitas yaitu diagram pareto dan diagram sebab akibat untuk mendapatkan penyebabpenyebab dari permasalahan. 


\section{Improve (perbaikan)}

Setelah akar penyebab masalah kualitas teridentifikasi maka perlu dilakukan penetapan rencana tindakan untuk melaksanakan peningkatan kualitas. Dalam perbaikan kualitas di sini digunakan metode Failure Mode and Effect Analysis (FMEA).

\section{E. Control}

Pada tahap terakhir ini, manajemen harus mempertahankan perubahan-perubahan yang telah dilakukan terhadap variabel-variabel $\mathrm{x}$ dalam usaha melestarikan hasil (Y) yang senantiasa memuaskan pelanggan.

\section{F. FMEA}

Failure Model and Effects Analysis (FMEA) adalah suatu prosedur terstruktur untuk mengidentifikasi dan mencegah sebanyak mungkin mode kegagalan. Suatu mode kegagalan adalah apa saja yang termasuk dalam kecacatan atau kegagalan dalam desain, kondisi di luar batas spesifikasi yang telah ditetapkan atau perubahan pada produk yang menyebabkan terganggunya fungsi fungsi dari produk tersebut.

FMEA adalah melakukan identifikasi serta memperkirakan semua kerusakan yang terjadi, dalam identifikasi tersebut dapat ditentukan besarnya RPN (Risk Priority Number). RPN adalah penilaian yang digunakan untuk menentukan prioritas berdasarkan kegagalan yang terjadi menurut Nilai RPN diperoleh dari hasil perkalian Severity (S) x Occurrence (O) x Detection (D). Penentuan nilai RPN berdasarkan kriteria yaitu:

1. Severity yaitu mengedintifikasi tingkat keseriusan akibat sebuah kerusakan yang dilihat dari sudut pandang keseluruhan sistem yang ada

2. Occurrence yaitu mengedintifikasi tingkat frekuensi atau keseringan terjadinya kerusakan.

3. Detection yaitu mengedintifikasi kemungkinan atau probabilitas bahwa suatu kerusakan dapat ditemukan.

\section{HASIL}

\section{A. Tahapan Define}

Pada tahap ini yang pertama kali dilakukan adalah menetapkan proyek yang akan dijalankan berdasarkan skala prioritas yang telah ditentukan, dan setelah itu kemudian menentukan Critical to Quality (CTQ). Jenis kecacatan produk karton box pada proses converting terdiri dari 5 kategori. Dalam penelitian ini data jenis kecacatan yang dikelompokkan dapat dilihat pada tabel 1:

Tabel 1 Critical to Quality (CTQ) Potensial Produk Carton Box

\begin{tabular}{ll}
\hline No & Jenis Kecacatan \\
\hline 1 & Pengeleman bagian kuping miring \\
2 & Cacat cetakan gambar \\
3 & Creasing pecah \\
4 & Salah pemasangan joint \\
5 & Layer rusak \\
\hline
\end{tabular}

Berdasarkan Tabel 1, kemudian diukur karakteristiknya serta kapabilitas dari proses pada saat ini untuk menentukan langkah apa yang harus diambil untuk melakukan perbaikan dan peningkatan selanjutnya.
Pengukuran ini meliputi pengolahan data pada DPMO (Defect Per Million Oppurtunities), nilai sigma, peta kontrol $\mathrm{P}$, diagram pareto dan cause and efek diagram.

\section{B. Tahapan Measure}

Tahap ini menggunakan acuan Critical to Quality (CTQ) yang telah didefinisikan pada tahap define sebelumnya. Pengukuran DPMO (Defect Per Million Opportunities) dan Nilai Sigma $(\sigma)$, sebagai berikut:

$$
\begin{aligned}
D P M O & =\frac{\text { defect }}{\text { unit } x \text { oppurtunity }} \times 10^{6} \\
& =\frac{137361}{724969 \times 5} \times 10^{6} \\
& =4202
\end{aligned}
$$

Dilakukan perhitungan untuk mencari nilai sigma $(\sigma)$, yang merupakan ukuran dari kinerja perusahaan yang menggambarkan kemampuan dalam menghasilkan produk bebas cacat. Berikut ini perhitungan nilai sigma untuk pada periode tahun 2019 adalah:

$$
\text { Nilai sigma } \begin{aligned}
(\sigma) & =\left(\frac{10^{6}-D P M O}{10^{6}}+1,5\right) \\
& =\left(\frac{10^{6}-4202}{10^{6}}+1,5\right) \\
& =4,13
\end{aligned}
$$

\begin{tabular}{|c|c|c|c|c|c|}
\hline Bulan & $\begin{array}{l}\text { Jumlah } \\
\text { produksi } \\
\text { aktual (PCS) } \\
\end{array}$ & $\begin{array}{l}\text { Jumlah } \\
\text { produk cacat } \\
\text { (pcs) }\end{array}$ & $\begin{array}{l}\text { Jumlah } \\
\text { CTQ }\end{array}$ & $\begin{array}{l}\text { Nilai } \\
\text { DPMO }\end{array}$ & $\begin{array}{l}\text { Nilai } \\
\text { sigma }\end{array}$ \\
\hline Jan & 724969 & 15235 & 5 & 4202 & 4,13 \\
\hline Feb & 807323 & 16451 & 5 & 4075 & 4,41 \\
\hline Mar & 539673 & 10105 & 5 & 3744 & 4,17 \\
\hline Apr & 714549 & 11123 & 5 & 3113 & 4,23 \\
\hline Mei & 694539 & 7113 & 5 & 2048 & 4,37 \\
\hline Jun & 452662 & 8813 & 5 & 3893 & 4,16 \\
\hline Jul & 772124 & 10634 & 5 & 2754 & 4,27 \\
\hline Agust & 735598 & 12199 & 5 & 3316 & 4,21 \\
\hline Sept & 709120 & 10714 & 5 & 3021 & 4,24 \\
\hline Okt & 722219 & 12514 & 5 & 3438 & 4,2 \\
\hline Nov & 617969 & 11145 & 5 & 3608 & 4,18 \\
\hline Des & 576688 & 11315 & 5 & 3924 & 4,15 \\
\hline Total & 8067433 & 137361 & 5 & 3405 & 4,2 \\
\hline
\end{tabular}

Rekapitulasi perhitungan untuk nilai DPMO dan nilai sigma dapat dilihat pada tabel 2:

Tabel 2 Rekapitulasi Perhitungan Untuk Nilai DPMO dan Nilai Sigma

Berdasarkan tabel 2 rata-rata nilai sigma di periode bulan Januari-Desember 2019 adalah 4,2. Nilai sigma tertinggi terajdi di bulan februari sedangkan nilai terendah di bulan januari. Pencapaian nilai sigma masih dibawah target karena nilai sigma yang bagus adalah jika nilai sigmanya mendekati nilai 6 , hal ini dikarenakan masih banyak ditemukan produk-produk cacat sehingga nilai DPMO masih tinggi yang mengakibatkan nilai sigma menjadi kecil. 
Peta kontrol dibuat untuk mengetahui apakah proses dalam kendali dan untuk memonitor variasi proses secara terus menerus. Peta $\mathrm{p}$ menggambarkan bagian yang ditolak karena tidak sesuai dengan spesifikasi yang diinginkan. Perhitungan untuk selama 12 bulan pada jenis kecacatan produk carton box. Bedasarkan data yang ada, didapat nilai mean $\mathrm{p}(\mathrm{CL})$ sebagai berikut:

$$
\begin{aligned}
\bar{p} & =\frac{\sum n p}{\sum n} \\
& =\frac{0,2058}{12} \\
& =0,0171
\end{aligned}
$$

Perhitungan UCL adalah sebagai berikut:

$$
\begin{aligned}
U C L & =\overline{\mathrm{p}}+3 \sqrt{\frac{\overline{\mathrm{p}}(1-\overline{\mathrm{p}})}{n}} \\
U C L & =0,0171+3 \sqrt{\frac{0,0171(1-0,0171)}{12}} \\
& =0,1293
\end{aligned}
$$

Perhitungan LCL adalah sebagai berikut:

$$
\begin{aligned}
L C L & =\overline{\mathrm{p}}-3 \sqrt{\frac{\overline{\mathrm{p}}(1-\overline{\mathrm{p}})}{n}} \\
L C L & =0,0171-3 \sqrt{\frac{0,0171(1-0,0171)}{12}} \\
& =-0,0951
\end{aligned}
$$

Nilai pada LCL yang minus dibuat menjadi 0 karena tidak ada kecacatan per produk unit yang minus jumlahnya. Berdasarkan hasil perhitungan batas kontrol (UCL) dan batas kontrol bawah (LCL), maka selanjutnya dapat dibentuk peta kontrol. Berikut ini adalah peta kontrol yang ditunjukan pada gambar 1 .

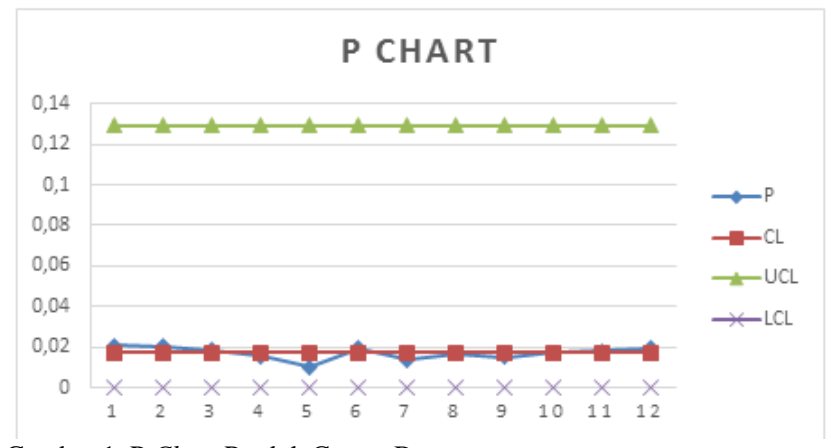

Gambar 1. P Chart Produk Carton Box

\section{Tahap Analyze}

Berikut ini adalah tabel 3 hasil dari pengolahan data untuk membuat diagram pareto.
Tabel 3 Jenis dan Jumlah Kecacatan Produk Carton Box

\begin{tabular}{|l|c|c|c|c|}
\hline Jenis Kecacatan & $\begin{array}{c}\text { Jumlah } \\
(\mathrm{pcs})\end{array}$ & $\begin{array}{c}\text { Komulatif } \\
(\mathrm{Pcs})\end{array}$ & $\begin{array}{c}\text { Presentase } \\
\text { Kecacatan }\end{array}$ & Komulatif \\
\hline Cacat cetakan gambar & 68.784 & 68.784 & 0,5008 & 0,5008 \\
\hline $\begin{array}{l}\text { Pengeleman bagian kuping } \\
\text { miring }\end{array}$ & 23.652 & 92.436 & 0,1722 & 0,6729 \\
\hline Creasing pecah & 22.812 & 115.248 & 0,1661 & 0,8390 \\
\hline Lay er rusak & 22.015 & 137.263 & 0,1603 & 0,9993 \\
\hline Salah pemasangan joint & 98 & 137.361 & 0,0007 & 1 \\
\hline Jumlah Cacat & 137.361 & & 1 & - \\
\hline
\end{tabular}

Berdasarkan perhitungan yang telah dilakukan pada tabel 3 dapat dibentuk diagram pareto, seperti pada gambar berikut:

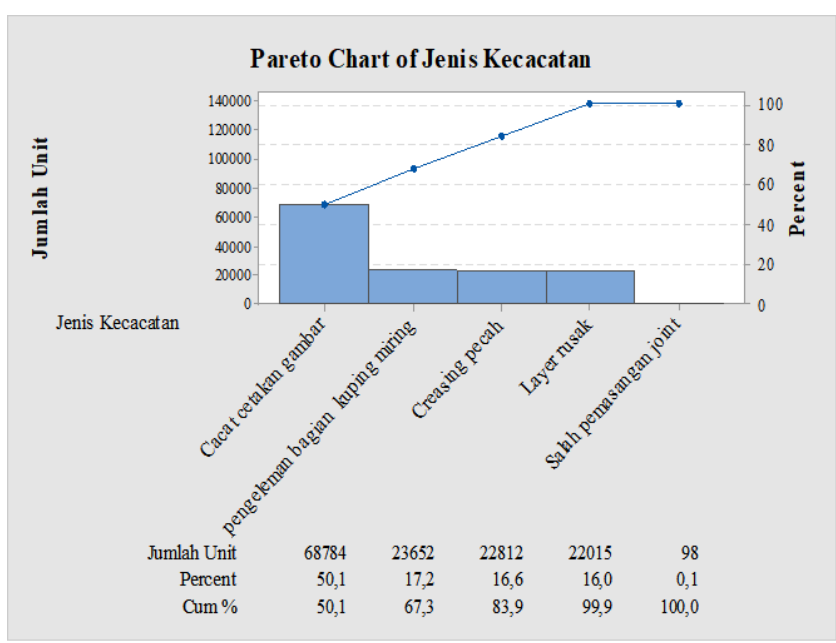

Gambar 2. Diagram pareto

Dari hasil diagram pareto dapat dilihat tingkat kecacatan produk carton box yaitu cacat cetakan gambar. Pada tahapan selanjutnya untuk melakukan analisa terhadap penyebab-penyebab tersebut dibantu dengan alat diagram Ishikawa atau diagram sebab-akibat. Diagram sebab-akibat digunakan untuk melihat penyebab-penyebab potensial dari permasalahan produksi carton box yang sering terjadi yang dapat dlihat pada gambar 3:

\section{Cause-and-Effect Diagram}

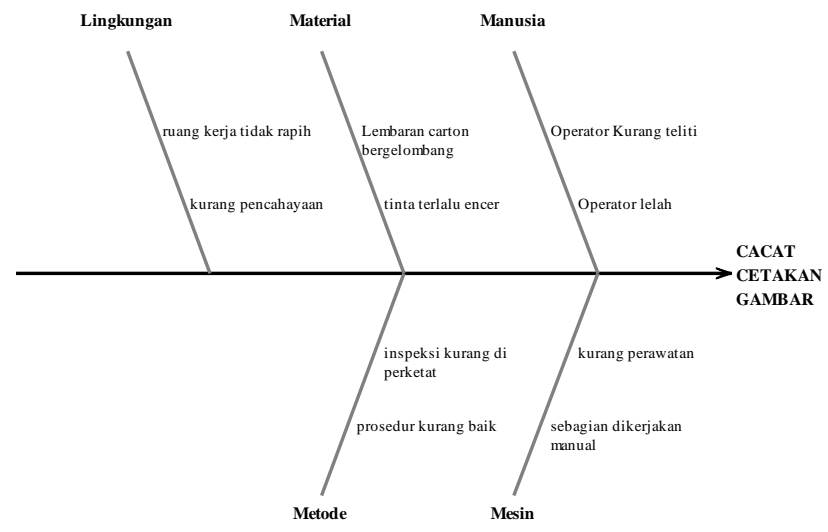

Gambar 3. Cause and Effect Diagram

Penyebab-penyebab yang menjadi akar permasalahan utama cacat cetakan gambar adalah:

1. Faktor manusia dikarenakan karyawan kurang teliti dalam mengamati hasil gambar cetakan printing dan kelelahan dalam bekerja sehingga kurang konsentrasi. 
2. Faktor material dikarenan terdapat lembaran carton yang berglombang yang dapat mengakibatkan hasil printing tidak sempurna dan penggunaan tinta yang terlalu encer sehinnga rentan sekali terhadap kualitas printing

3. Faktor lingkungan dikarenakan ruang kerja tidak rapih dapat mengakibatkan ketidaknyamanan dalam bekerja dan kurangnya pencahayaan sehingga kurangnya penglihatan untuk mengamati terhadap produk yang dalam proses.

4. Faktor Mesin dikarenakan kurangnya perawatan sehingga mengurangi performa mesin longway tersebut dan pengerjaan masih ada yang menggunakan dengan cara sablon manual.

5. Metode dikarenakan prosedur yang kurang baik dan inspeksi yang kurang diperketat sehingga terdapat produk yang dikembalikan oleh costumer karna tidak sesuai dengan spesifikasi.

\section{Tahap Improve}

Pada tahap improve akan diberikan usulan-usulan yang akan dapat membantu dalam mengurangi kegagalan dalam produksi pada produk carton box. Perbaikan tersebut ada yang menjadi implementasi dalam penelitian dan juga ada yang menjadi usulan perbaikan terhadap pabrik. Usulan yang direkomendasikan adalah pengawasan dengan tujuan untuk menjadikan operator bekerja sebagaimana yang diharapkan, dibutuhkan kegiatan pengawasan agar penyimpangan dapat segera diketahui dan diperbaiki. Pengawasan akan mengusahakan agar terjadinya penyimpangan menjadi sekecil mungkin.

\section{E. Tahap Control}

Pada tahap control ini hasil-hasil perbaikan di dokumentasikan dan disebarluaskan. Perbaikan yang sukses dalam peningkatan proses distandarisasikan dan dijadikan pedoman kerja standar. Selanjutnya perusahaan harus melakukan peningkatan terus menerus pada jenis masalah lain yang timbul melalui konsep DMAIC.

\section{F. FMEA}

Data yang digunakan untuk membuat FMEA ini diambil analisa akar permasalahan yang di dokumentasikan dalam diagram cause and effect diagram. Berikut adalah tabel 4 hasil dari FMEA.

Tabel 4 Perhitungan FMEA

\begin{tabular}{lllllll}
\hline \multirow{2}{*}{ Aspek } & $\begin{array}{l}\text { Potential Failure } \\
\text { Mode }\end{array}$ & S & O & D & RPN & Rangking \\
\hline \multirow{2}{*}{ Manusia } & $\begin{array}{l}\text { Operator kurang } \\
\text { teliti }\end{array}$ & 5 & 7 & 8 & 280 & 1 \\
& $\begin{array}{l}\text { Operator lelah } \\
\text { Metode }\end{array}$ & 6 & 4 & 8 & 192 & 2 \\
& $\begin{array}{l}\text { Prosedur kurang } \\
\text { baik }\end{array}$ & 5 & 5 & 5 & 125 & 2 \\
& $\begin{array}{l}\text { Inspeksi kurang } \\
\text { diperketat }\end{array}$ & 4 & 4 & 4 & 64 & 3 \\
Mesin & $\begin{array}{l}\text { Kurang perawatan } \\
\text { Pengerjaan }\end{array}$ & 4 & 4 & 3 & 48 & 4 \\
& $\begin{array}{l}\text { manual } \\
\text { Lembaran carton }\end{array}$ & 4 & 4 & 3 & 48 & 4 \\
bergelombang & $\begin{array}{l}\text { Minta terlalu encer } \\
\text { Tintal }\end{array}$ & 3 & 3 & 3 & 27 & 5
\end{tabular}

\begin{tabular}{|c|c|c|c|c|c|}
\hline ingkung & $\begin{array}{l}\text { Ruang kerja tidak } \\
\text { rapih dan kurang } \\
\text { pencahayaan }\end{array}$ & 3 & 3 & $J$ & 27 \\
\hline
\end{tabular}

Berdasarkan perhitungan RPN pada tabel 4, didapatkan potential failure mode dengan nilai RPN tertinggi yaitu operator kurang teliti dan lelah dalam bekerja yang merupakan aspek dari sisi manusia dengan nilai RPN 280. Nilai tersebut merupakan mode kegagalan paling kritis dan dijadikan sebagai prioritas pertama sehingga perlu dilakukan tindakan korektif segera.

\section{KESIMPULAN}

Faktor-faktor yang menyebabkan kecacatan produk adalah manusia, berdasarkan hasil perhitungan dengan menggunakan metode FMEA menghasilkan nilai RPN tertinggi yaitu operator kurang teliti dengan nilai 280. Jenis kecacatan yang paling dominan berdasarkan hasil diagram pareto, terjadi pada proses produksi carton box adalah cacat cetakan gambar yaitu sebanyak 68.784 pcs dengan nilai prosentase sebesar 50,1\% dari total kecacatan yaitu sebanyak 137.361 pcs. Usulan-usulan yang akan dapat membantu dalam mengurangi kegagalan pada produksi carton box. Berdasarkan hasil analisis FMEA, diperlukan adanya pengawasan agar proses produksi sesuai dengan standar prosedur dengan tujuan mengusahakan agar terjadinya penyimpangan menjadi sekecil mungkin.

\section{REFERENCES}

[1] Rusdiana, Manajemen Operasi, 1st ed. Bandung: CV PUSTAKA SETIA, 2014.

[2] I. R. Rohami Nst, Khawarita, and Anizar, "Usulan Perbaikan Kualitas Produk Mie Instan Dengan Metode Six Sigma (DMAIC) Dan Failure Mode and Effect Analysis (FMEA) DI PT. XY," J. Tek. Ind. FT $U S U$, vol. 8, no. 2, pp. 31-35, 2013.

[3] D. Caesaron, S. Yohanes, and P. Simatupang, "Implementasi Pendekatan DMAIC untuk Perbaikan Proses Produksi Pipa PVC (Studi Kasus PT. Rusli Vinilon),” J. Metris, vol. 16, pp. 91-96, 2015.

[4] E. Sumarya, "Perbaikan Proses Produksi Botol Kemasan AMDK dengan Pendekatan DMAIC (Studi Kasus PT. Lautan Bening) The Improvement of AMDK Bottle Packaging Production Process with DMAIC approach (A Case Study PT. Lautan Bening)," PROFISIENSI, vol. 4, no. 2, pp. 68-78, 2016.

[5] M. H. I. N. Asnan and F. Fahma, "Penerapan Six Sigma Untuk Minimalisasi Material Scrap Pada Warehouse Packaging Marsho PT. SMART Tbk. Surabaya," Performa Media Ilm. Tek. Ind., vol. 18, no. 1, pp. 1-8, Jul. 2019, doi: 10.20961/performa.18.1.21764.

[6] S. Nasution and R. Desiana Sodikin, "Perbaikan Kualitas Proses Produksi Karton Box Dengan Menggunakan Metode DMAIC Dan Fuzzy FMEA,” J. Sist. Tek. Ind., vol. 20, no. 2, pp. 36-46, 2018.

[7] A. Rahman and S. Perdana, "Analisis Produktivitas Mesin Percetakan Perfect Binding Dengan Metode OEE dan FMEA," J. Ilm. Tek. Ind., vol. 7, no. 1, pp. 34-42, 2019.

[8] E. Rusmiati, "Penerapan Fuzzy Failure Mode And Effect Analysis (FUZZY FMEA) Dalam Mengidentifikasi Kegagalan Pada Proses Produksi Di PT Daesol Indonesia," J. Teknol. dan Manaj., vol. 10, no. 2, pp. 1-21, 2012.

[9] Z. F. Hunusalela, S. Perdana, and R. Usman, "Analysis of productivity improvement in hard disc spare parts production machines based on OEE, FMEA, and fuzzy value in Batam," in IOP Conference Series: Materials Science and Engineering, 2019, vol. 508 , no. 1 .

[10]N. Badariah, D. Sugiarto, and C. Anugerah, "Penerapan Metode Failure Mode And Effect Analysis (FMEA) dan Expert System (Sistem Pakar)," in Seminar Nasional Sains dan Teknologi 2016, 2016, pp. 1-10.

[11]M. Basori and Supriyadi, "Analisis Pengendalian Kualitas Cetakan Packaging Dengan Metode Failure Mode and Effect Analysis (FMEA)," in Seminar Nasional Riset Terapan 2017, 2017, vol. 25 , pp. 158-163. 
